to co-operate in any proceeding which may be thought most 1 ikely to induce the Government of the United States to continue the publication of them.

Town Museum, Leicester, March 7

\section{Origin of the Screw Propeller}

I sHoULD like to remark, in reference to last week's letter on the origin of the screw propeller, that I have long considered the pectoral fins, which are so extremely useful to and prominent upon soles, or the family Plentronectide, as being highly suggestive of this more modern mode of propulsion. Anyone who likes to watch these extremely interesting fish in their swimming movements and gracefal gyrations may witness the action and I think attribute to its movements more than is possihle in the case of ash and other seed vessels.

Valentines

\section{WILIIAM EARLEY}

\section{The Three Kingdoms of Nature}

IN reply to your correspondent's question as to which of the three king loms " water" belongs, I bes to state that the strict scientific definition of a mineral, adopted in most mineralogies, is as follows : a mineral is any inorganic, homogeneaus, natural substance.

This definition obviously includes water, which is accordingly always described in books on mineralogy; and the fact of water being a liquid at ordinary temperatures cannot of course exclude it from the list of minerals. Indeed, in some mineralogies, gases-such as carbonic acid, sulphurous acid, and even the air -are described as minerals. Water, like many other minerals, can exist in more than one form ; thas, if the temperature of our globe were much lower than it is, we should only have water in the form of the transparent crystalline solid, known as ice, which - like other minerals, such as sulphur, metallic lead, metallic mercury, \&c.-has its own particular point of fusion; thus : sulphur melts at $226^{\circ} \mathrm{F}$., water at $32^{\circ}$, mercury at $39^{\circ}$. All these substances still further resemble one another in their capability of being converted into a gaseous form, at certain fixed temperatures. These facts - with many others-prove water to be as much a mineral as calcite or gypsum.

E. G. C.

Upper Holloway, N., March I3

The Recent Storm

YeSTERDAY's storm appears to have been a true cyclone, and to have passed nearly centrally over here about half.past one o'clock. I first noticed the barometer at II A.M. I forward observations :-

\begin{tabular}{|c|c|c|c|}
\hline $\begin{array}{l}\text { Sunday. } \\
\text { Io }\end{array}$ & & Wind and rain $\mathrm{S}$ & Barometer. \\
\hline II & , & Strong ditto & 27 \\
\hline 12 & & Ditto from S.W. & $26 \cdot 9$ \\
\hline 12.30 & P.M. & Increased ditto... & 2685 \\
\hline I &, & Great gale, S.W. & $26 \cdot 8$ falling still. ${ }^{1}$ \\
\hline 1.20 & 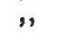 & Ditto, S.W. $\quad \ldots$ & At \\
\hline I. 35 & " & Calm $\ldots, \ldots, \ldots$ & lunch. \\
\hline 2 & $"$ & $\begin{array}{l}\text { Sirong wind from } \mathrm{N} \text {. } \\
\text { with driving sleet.... }\end{array}$ & 26.8 rising. \\
\hline 2.30 & ", & Gale, snow and sleet. & 26.85 \\
\hline 3 & " & Ditto, rather increased & $26 \cdot 9$ \\
\hline 4 & $"$ & Brisk breeze, N. $\quad \ldots$ & 27 \\
\hline 5 & ", & Slight breeze, N. & $27 \cdot 35$ \\
\hline I I & , & $\begin{array}{llll}\cdots & \cdots & \cdots & \cdots\end{array}$ & 279 \\
\hline
\end{tabular}

Staplehurst, Kent, March 13

T. S. USBORNE

Bed-time

CAN any of your readers inform me on what ground the fol lowing saying is based, and to what extent it is true :- "One hour's sleep before twelve is worth two after."

March Io

VITA BREVIS

\section{OUR ASTRONOMICAL COLUMN}

COMET I840 (II.).--In Astronomische Nachrichten, No. 2,079, Dr. Kowalczyk, of Warsaw, publishes his investigation of a definitive orbit for the comet discovered at Berlin, by Prof. Galle, the present Director of the Observatory at Breslau, on the $25^{\text {th }}$ of January, I 1840 . s N.B. - This is $x^{2}$ lower than I ever saw it before.
This comet, which was last observed at Kremsmunster on the Ist of April, had already been made the subject of extensive calculation by Professors Plantamour and Loomis. The former, in 1843 , discussing his own series of careful observations taken at Geneva, found (Astron. Nach., No. 476) that a parabolic orbit represented the comet's course within the probable limits of error of observation; on including the series taken at Berlin he found the most probable orbit to be an ellipse, but of great excentricity to which little weight was considered to attach. Loomis, on his side, taking into account the effect of planetary perturbation during the interval of the comet's visibility, also found an ellipse, but with a more moderate excentricity, the period of revolution being about 2,420 years; the sum of the squares of the errors in the ellipse is diminished to one-third of the amount with the best determinable parabola. Loomis's investigation will be found in the "Transactions of the American Academy," vol. viii.; his orbits are not included in the extensive collection in Dr. Carl's "Repertorium der Cometen-Astronomie," a work which, notwithstanding its great utility to the student of this branch of the science, is yet not complete or free from numerical errors.

Kowalczyk starts with the parabolic elements obtained by Plantamour in 1843 , comparing them with the whole course of obsecvations. After introducing the corrections for aberration and parallax, and the earth's positions from Leverrier's tables, instead of those from the Tables of Carlini use $d$ by previous computers and by the usual method of equations of condition for ten normal places, he finally arrives at an elliptical orbit, very closely agreeing with observation, and showing a period of revolution of 3,789 years.

BERLINER ASTRONOMISCHES JAHRBUCH, I878.- - The Berlin Ephemeris for 1878 has been received during the past week. In its speciality-the ephemerides of the minor planets--Prof. Tietjen has evidentiy made a very vigorous and successful effort to keep pace with the frequent additions to the list; his volume contains approximate places for every twentieth day during the present year of 144 of the 160 small planets hitherto detected, and accurate opp ssition ephemerides of $7 \mathrm{r}$, occupying together one-third of the entire work. The collective table of elemeats to No. I47 inclusive is not the least important part of this volume of the Fahrbuch.

Prof. Tietjen continues to transfer to the Berlin workof course after reduction to that meridian-the places of the moon from our Nautical Almanac, which, by order of the Admiralty, is invariably published three complete years in advance of that to which it applies, and considerably earlier than any other of the national ephemerides. The economy of labour of computation thereby effected, which is probably found by the conductor of the Berliner Fahrbuch of material assistance for the production of his extensive work on the minor planets, might possibly be extended in other directions. An ephemeris of the moon from Hansen's Tables, employed for all the European ephemerides, admits of pretty complete check at a small expense of calculation, and there appears to be no advantage derivable from an independent work involving such heavy labour as the computation of the moon's positions through a whole year. Prof. Tietjen contents himself with a few direct calculations from the Tables which he says "invariably exhibit a satisfactory agreement" with the results in the Nautical Almanac.

\section{PHYSICAL SCIENCE IN SCHOOLS}

$W^{H E N}$ I claimed for science a position of educational equality "both as regards range and time with classics and mathematics," I intended to express the amount of science teaching in the school curriculum which alone can satisfy the upholders of a scientific education. I am as fully aware as Mr. Wilson is of the 
importance of a firm mathematical foundation, and I am as far from wishing to overwhelm the younger boys with science before they have mastered the elements of arithmetic and grammar and languages as he can be. My experience amongst boys has, however, not been such as to enable me to say exactly when a thorough science teaching ought to begin.

The mistake, as it seems to me, which is prevalent respecting science teaching in schools, is the notion that it is a subject to be lectured upon for two hours per week to those already educated, and who show an aptitude for it, whilst it can, and ought to, be introduced at a definite period as a regular part of school work. It is now usually made an extra subject, a quasi-amusement, put on the same footing as drilling or drawing, whilst it can, and ought to, be made as much a discipline as the Latin grammar or Euclid, affording, as it does, in my opinion, if properly taught, an excellent training ground for acquiring that reasoning power and habit of application which it is usually supposed can only be gained through one or other of these older channels. I am sorry that Mr. Wilson thinks that any man of science is misleading public opinion on this subject. This is a serious charge, but as it rests on a misconception, I remain convinced that in the long run public opinion will endorse our views.

It is out of my power to tell Mr. Wilson whose business it is to make the change to a better state of things, which he himself feels to be necessary, for he admits that the new examination is adverse to scientific education. I do, however, feel strongly that unless the authorities of our great schools and the examining Boards set earnestly to work to introduce this new discipline and give it (as many of them to their honour are now beginning to do) a fair field and no favour, the beneficial influence which these schools have had on English education, must soon begin to diminish.

The Balliol scholarships and the other great University "advertisements" I believe to be in many ways stumbling-blocks in the path of true education in this country; "the many," as Mr. Wilson truly says, "are kept to swell the triumph of the few," and the prizes have to be got "at any cost to boy or school." Are we never to break loose from this degrading bondage to the Moloch of examination? I for one think better both of commissioners, governors, and head-masters, and look forward with hope to the ultimate emancipation of school-boys from their ancient fetters. Then those subjects will be taught at school which are best suited to make the mass of boys good citizens, and to forward the highest interests of the country, instead of the great aim of the schoolmaster being to secure a Balliol scholarship. We shall then see less than we do now of University men taking to sheepfarming in Australia, and hear less complaint of the superiority of our continental friends both in pure science and its application.

HENRY E. ROSCOE

\section{PROF. FLOWER'S HUNTERIAN LECTURES ON THE RELATION OF EXTINCT TOEXIST. ING MAMIMALIA ${ }^{1}$}

\section{IV.}

$\mathrm{T}$ was mentioned in the last lecture that no true Proboscideans have been found below the Miocene strata, but among the most remarkable of the numerous recent discoveries in the Eocene formations of Wyoming Territory, North America, has been that of a group of animals of huge size, approaching, if not equalling, that of the largest existing elephants, presenting a combination of characters quite unlike those known among either recent or extinct creatures, and of which there were evidently

I Abstract of a course of lectures delivered at the Royal College of Surgeons "On the Relation of Extinct to Existing Mammalia, with Specia Reference to the Derivative Hypothesis," in conclusion of the coursed
"(Sec Reports in NATURE for that year.) Continued from p. 356 . several species living contemporaneously. To form some idea of their appearance, we must imagine animals very elephantine in their general proportions, elevated on massive pillar-like limbs, with the same complete radius and ulna, the same short, round, five-toed feet which distinguish the elephants from all other known hoofed quadrupeds. The tail, as in the elephants, was long and slender, but the neck, though still short was not so much abbreviated as in modern Proboscideans, and there is no good evidence of their having possessed a trunk. The brain was exceedingly small for the size of the creature. Ths head differed greatly from that of the elephants, being long and narrow, more like that of a rhinoceros, and, as in that animal, was elevated behind into a great occipital crest, but unlike that or any other known mammal, it had developed from its upper surface, three pairs of conspicuous laterally diverging protuberances, one pair from the parietal region, one over or in front of the orbits, and one near the forepart of the elongated nasal bones. Whether these were merely covered by bosses of callous skin, as the rounded form and ruggedness of their extremities would indicate, or whether they formed the bases of attachments for horns of still greater extent, either like those of the rhinoceros or the cavicorn ruminants, must still be a matter of conjecture. But in either case they must have given a very strange aspect to the creature which possessed them, and have been formidable weapons in encounters either with animals of its own kind, or with the fierce carnivorous beasts whose remains are associated in the same deposits with them. There were no incisor teeth in the upper jaw, but a pair of huge descending canine tusks very similar in position and form to those of the musk-deer. Behind these, and at some distance from them, were, on each side above and below, six molar teeth of comparatively small size, placed in continuous series, each with a pair of oblique ridges, conjoined internally, and diverging externally in a V-like manner, and with a stout basal cingulum. The lower incisors and canines were small, and are only known at present by their sockets. The dental formula is-

$$
i \frac{\mathrm{o}}{3} c \frac{\mathrm{I}}{\mathrm{I}} p \frac{3}{3} m \frac{3}{3}=34 \text {. }
$$

The first discovered evidences of the existence of animals of this group were described by Leidy in 1872 , under the name of Uintatherium, from the Uintah Mountains, at the base of which they were found. Very shortly afterwards other portions of bones and teeth of either the same or closely allied forms, were described by Marsh as Dinoceras, and by Cope as Loxolophodon and Eobasileus. Whether these names will ultimately be retained for separate generic modifications, or whether they will have to be merged into the first, it would be premature to attempt to decide upon the evidence before us. A more important question is, what are the affinities of the animals, and what light do they throw on the general evolutionary history of the class to which they belong? Looking at the totality of their organisation as already known, at first sight they seem to present a considerable resemblance with the Proboscidea. The absence of the third trochanter, and of the fossa for the ligamentum teres on the femur, and the general form of the feet with their short broad toes are quite Proboscidean characters, but a closer examination of the structure of the carpus and tarsus, especially of the mode of union of the different bones with each other, shows more essential affinities with Rhinoceros. The same may be said of the cranium, so that on the whole they appear to come nearer to the Perissodactyle Ungulates than was formerly supposed. This relationship is strengthened by the discovery of other forms, constituting the genera Bathmodon and $\mathrm{Me}$ talophodon of Cope, of earlier geological age, which with the same general structure of the Uintatheriide retain in a most interesting manner many primitive characters, especially the complete number of incisor and premolar 